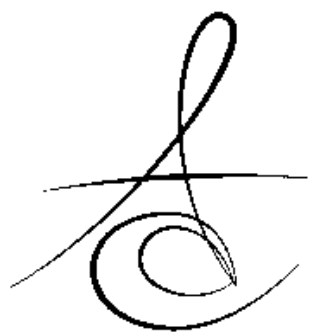

\title{
HORLAMA VE OBSTRUKTİF UYKU APNESİ TEDAVİSİNDE ORAL APAREY KULLANIMI
}

\author{
THE USE OF ORAL APPLIANCES IN TREATMENT OF SNORING AND \\ OBTRUCTIVE SLEEP APNEA
}

\author{
Arş. Gör. Dt. Eda ÖZDERE*
}

Prof.Dr. Filiz AYKENT*

Makale Kodu/Article code: 1741

Makale Gönderilme tarihi: 18.06.2014

Kabul Tarihi: 13.10 .2014

\section{ÖZET}

Amaç: Bu derleme üst solunum yollarının anatomisini kavrayarak bu alandaki bozukluğa bağlı gelişen horlama ve obstruktif uyku apnesi sendromunun (OUAS) teşhis yöntemleri, tedavi seçenekleri, tedavide kullanılan oral aparey çeşitleri ve yapım yöntemleri hakkında diş hekimlerine bilgi verme amacını taşımaktadır. OUAS hastalarında tanı ve tedavi seçeneklerini gözden geçirerek bu hastalara karşı diş hekiminin yaklaşımının ne olması gerektiği de incelenmiştir. OUAS toplumda daha sıklıkla özellikle orta yaş üstü erişkinlerde görülen bir bozukluktur. OUAS ve horlama tedavisinde cerrahi ve diğer tedavi yöntemlerine alternatif olarak oral apareylerin kullanımı, non-invaziv ve uygulaması daha kolay bir tedavi seçeneği olması sebebiyle günümüzde oldukça popüler hale gelmiştir.

Anahtar sözcükler: Obstruktif uyku apnesi, oral apareyler, horlama.

\section{ABSTRACT}

This article aimed to help dentists to understand the anatomy of upper airway, the diagnosis and treatment options of snoring and obstructive sleep apnea and the oral appliance types used in treatment. This article invastigates the treatment options and diagnosis of OUAS patients and reviews the clinical approach of dentists. OUAS is a sleeping disorder commonly seen in middle aged and older adult population. Dental devices became more popular in the treatment of obstructive sleep apnea and snoring. These devices are non-invasive and easy to apply comparing to other surgical treatment options.

Key words: Obstructive sleep apnea, oral appliances, snoring

\section{Gíriş}

Obstruktif uyku apnesi, toplumda erkeklerin \%4'ünde kadınların ise \%2'sinde görülen, uyku sırasında üst hava yollarında tekrarlayan tıkanmalar ile karakterize bir uyku bozukluğudur., ${ }^{1,2}$ Tıkanmalar nedeniyle meydana gelen kan oksijen saturasyonundaki düşüş hastalarda morbidite ve mortalitenin artmasına yol açmaktadır. ${ }^{2,3}$

Obstruktif apne sendromunu (OUAS) ilk kez 1889 yılında William Hill ağız solunumu yapan, baş ağrısı ve horlama şikayeti olan öğrencilerde tanımlamıştır. ${ }^{4}$ 19. Yüzyılda Charles Dickens, uyku apne sendromunun tüm özelliklerine uyan şişman, uyku sırasında horlayan ve moraran, gündüzleri uyuklayan ve konsantrasyon bozukluğu gösteren, toplumsal ilişkilerinde sorunlar yaşayan insanlardan 'Pickwickian Paper' adlı kitabında bahsetmiştir. ${ }^{5}$ Uyku apnesi daha sonra 1973 yılında yeni bir sendrom olarak Guilleminault tarafından yeniden tanımlanmıştır. ${ }^{6}$

\section{Üst Solunum Yolu Anatomisi}

Üst solunum yolu, OUAS açısından en önemli bölüm olan farenksi de içeren, burun deliklerinden başlayarak trakea'ya uzanan yapılardan oluşur. Farenks; hipofarenks, orofarenks ve nazofarenks olmak üzere 3 ana bölgeden oluşmaktadır: ${ }^{7}$

1) Hipofarenks: Larenks ve dil kökü arasında yer alır.

2) Orofarenks: Hipofarenks ve nazofarenks arasındadır ve 2 bölgeye ayrılır.

\footnotetext{
* Selçuk Üniversitesi Diş Hekimliği Fakültesi / Protetik Diş Tedavisi A. D
} 
a) Retropalatal bölge (Velofarenks): Sert damak ve yumuşak damağın distal sınırı arasında yer alır.

b) Retroglossal bölge: Epiglot ile yumuşak damağın distal sınırı arasında yer alır.

3) Nazofarenks: Nazal konkalar ve sert damak arasında yer alır ${ }^{7}$ (Resim 1$)$.

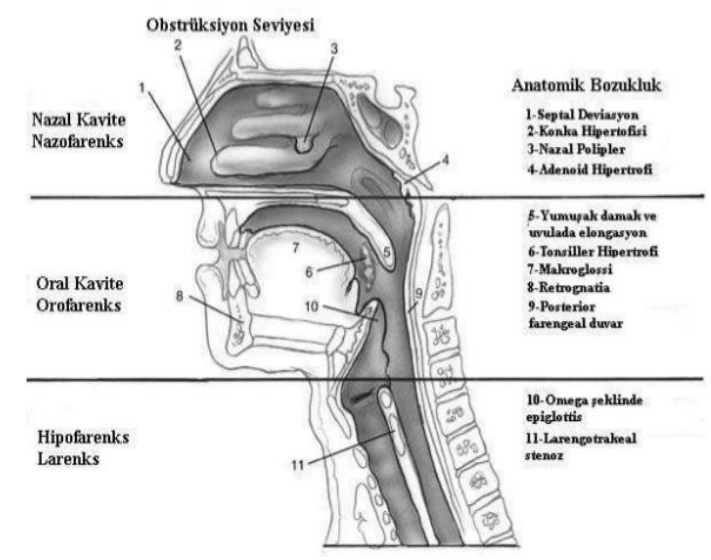

Resim 1. Üst Solunum Yolu Anatomisi ve Görülen Anatomik Bozukluklar

\section{Etyoloji}

OUAS multifaktöriyel etyolojiye sahip, sıklıkla orta yaşlarda ve daha çok erkeklerde görülen bir hastalıktır. 1,7-10 Mikrognati, retrognati, makroglossi, çeşitli KBB hastalıkları, kraniofasial formdaki değişiklikler, kas aktivitesinde yetersizlik, yumuşak doku anomalileri, alkol ve antidepresan ilaçların kullanımı ve obezite OUAS etyolojisinde rol oynayan faktörlerdendir. ${ }^{711-13}$ OUAS'ın en belirgin semptomlarından biri horlamadır. Horlama üst hava yollarındaki daralma nedeniyle artan hava akımına bağlı bölgedeki yumuşak dokuların vibrasyonu ile oluşur. Her OUAS hastasında horlama görülür fakat her horlayan hastaya OUAS tanısı konulamaz. ${ }^{14}$

\section{Horlama}

Horlamanın yetişkin nüfusun \% 40’nı, erişkin erkeklerin ise yaklaşık \% 25'ini etkilediği düşünülmektedir. ${ }^{15-17}$ Horlama ve OUAS'ın, erkek populasyonunda görülme sıklığı kadınlardan yaklaşık iki kat fazladır; bunun olası sebebi kadınlarda yağ birikiminin çoğunlukla vücudun alt kısmında, erkeklerde ise vücudun üst kısmında özellikle de boyun bölgesinde olmasıdır. Orta yaş popülasyonununda bayanların \% 2'sinde, erkeklerin ise \%4-10'unda uyku apnesi ve horlamadan etkilenmektedir. ${ }^{15,17}$ Aşırı yağ birikiminin
OUAS gelişiminde negatif etkisi olduğu bilinmektedir. Diğer bir önemli etyolojik faktör ise, üst solunum yolu boyutlarını etkileyerek OUAS ve horlamaya sebep olan uyku pozisyonudur. ${ }^{18}$

Yoshida' nın ${ }^{19}$ 1998'de yapmış olduğu çalışmaya göre; sırt üstü pozisyonda çiğneme ve dil kaslarının hipotonisi ve bunun yanında mandibulanın ağırlığı ağzın açılmasına neden olurken, mandibula ve dil dorsal yönde yer değiştirerek faringeal daralmaya, solunum yolu direncine, horlamaya ve obstruktif apneye sebep olabilmektedir. Araştırmacı, horlama ve/veya obstrüktif uyku apnesi olan hasta gruplarında sırt üstü pozisyonda, masseter ve submental kasların kasılması ile nefes alıp vermenin sonunda, ağız açıklığının normal bireylere göre daha fazla arttığını bildirmişdir. Bu durum da, uyku pozisyonunun horlama ve OUAS'a neden olabilecek faktörlerden biri olduğunu gösterir. $\mathrm{Bu}$ yüzden hastaların yanlış uyku alışkanlıkları düzeltilip doğru uyku pozisyonlarında uyumalarının sağlanması tedavinin en önemli basamaklarından biridir. ${ }^{18}$

\section{OUAS Tanısı}

OUAS'ın en önemli tanı yöntemi uyku laboratuvarında gece boyu alınan polisomnografi (PSG) lerdir. ${ }^{1}$ Diğer tanı yöntemleri olarak fleksible nasofaringoskopi, çene elektromyogramı, akustik refleksiyon, sefalometri, floroskopi, bilgisayarlı tomografi (CT), manyetik rezonans (MR), elektro-okulogram, thermistor, elektrokardiyogram, pulse oksimetri sayılabilir. Daha güç fark edilen solunum olaylarını tanımlamakta nazal basıncın ölçümü yardımcı olabilir. ${ }^{2,20}$

OUAS tanısında "altın standart" olan PSG'dir." Ancak ülkemizde ve dünyada uyku bozuklukları ile ilgili yeterli düzeyde çalışma yapabilecek laboratuar sayısı oldukça kısıtlıdır. Bu nedenle OUAS'dan şüphelenilen olguların seçiminde, kesin tanı koydurmasa da pahalı, zaman alıcı ve özel ekipler gerektiren bir yöntem olan PSG öncesinde diğer tanı yöntemlerinden faydalanmak gerekir. $^{20}$

\section{OUAS Tedavisi}

OUAS'ın tedavisi, içerisinde KBB ve baş-boyun cerrahisi hekimi, nörolog, psikiyatrist, prostodontist, göğüs hastalıkları hekimi, ortodontist ve maksillofasiyal cerrahı bulunan bir ekiple yapılmaktadır. Fakat OUAS tedavisinde hiçbir modern tedavi yönteminin komplikasyonsuz olarak yüksek başarı oranı sağlayamadığı bildirilmiştir. ${ }^{7,16}$ OUAS için tedavi seçenekleri aşağıdaki gibi sıralanabilir: ${ }^{21,22}$ 


\section{1) Davranışsal Modifikasyonlar:}

Cerrahi olmayan non-invaziv tedaviler; baş ve boyun ekstansiyon boyunlukları yardımıyla kafa postürünü değiştirmek ve uyku ortamı-uyku pozisyonu değişiklikleri gibi konservatif yaklaşımları içerir. ${ }^{16,24}$ Diğer davranışsal modifikasyonlar ise kilo vererek vücut ağırlığını azaltmak, sigara-alkol (özellikle gece) sedatif ve hipnotik ilaç (merkezi sinir sistemi depresörleri) kullanımından kaçınmaktır. ${ }^{23}$

2) Nazal Sürekli Pozitif Solunum Yolu BasıncI (NCPAP):

Uyku esnasında yüze yerleştirilen bir maske yardımıyla üst hava yollarına pozitif hava basıncı veren bu cihazın, OUAS tedavisinde etkinliği kanıtlanmış ve altın standart olarak kabul edilmiştir. ${ }^{1}$ Fakat aygıtın retansiyonunun zayıf olması, çok gürültülü olması, buruna verilen basınçlı havanın oluşturduğu rahatsızık hissi, ağız ve burun mukozasında oluşturduğu kuruluk gibi nedenlerden dolayı hastalar tarafından kolay tolere edilememektedir. ${ }^{7}$

Cihazın 4-6 hafta düzenli kullanım sonucunda farengeal hacimde artma ve dil hacminde azalma olduğu bildirilmiştir. NCPAP aygıtı oral apareylerle birlikte de kullanılabilir ve oral apareylerinin tedavi başarısını arttıır.r. ${ }^{724-27}$

NCPAP tedavisi aşağıdaki durumlarda uygulanabilmektedir: ${ }^{28}$

a) Semptomları göz önüne alınmaksızın apne hipopne indeksi (AHI) en az 20 olan olgular.

b) Apne Hipopne İndeksi (AHI) en az 10 olan ve gündüz aşııı uyku hali olan olgular.

c) Solunumsal arousal indeksi en az 10 olan ve gündüz aşırı uyku hali olan olgular.

Bilevel CPAP (BPAP) ise tüm solunum sabit basınç yerine siklusu boyunca inspirasyon ve ekspirasyonda farklı pozitif basınç uygulayan bir aygıttır. Yapılan çalışmalar sonucunda komplikasyon açısından NCPAP ve BPAP arasında anlamlı fark olmadığı, NCPAP' In OUAS' da altın standart tedavi yöntemi olduğu bildirilmiştir. ${ }^{1,29}$

\section{3) Cerrahi Tedavi:}

OUAS tedavisi için Amerikan Uyku Bozuklukları Birliğinin (1996) önerdiği cerrahi işlemler: lazer destekli uvulaplasti (LAUP), uvulapalatofaringoplasti (UPPP), palatofaringoglossoplasti, uvulapalatal flap, tonsillektomi-adenoidektomi (adenotonsiller hipertrofinin OAS'a neden olduğu çocukların tedavisinde), uvulapalatofaringoglossoplasti, somnoplasti veya radyofrekans (RF) ile dil ve/veya yumuşak damakuvula dokularının hacimsel küçültülmesi, koter destekli palatal sertleştirme operasyonu, epiglottidektomi (eptoplasti) ve linguoplasti ile birlikte laser destekli orta hat glossektomi gibi faringeal yumuşak doku cerrahileridir. ${ }^{721,30}$

\section{4) Oral Apareyler:}

Dil ve mandibulanın pozisyonunu değiştiren oral apareyler basit horlamada, üst hava yolu rezistans sendromunda, kilo verme-uyku pozisyonunda değişim gibi davranış modifikasyonlarına cevap vermeyen hafif dereceli OUAS hastalarında, cerrahi ve NCPAP tedavilerini reddeden veya bu tedavileri tolere edemediği için yarım bırakan orta-ağır dereceli OUAS vakalarında endikedir. ${ }^{31,32}$ Oral aparey tedavisini sadece minor klinik semptomları olan hafif dereceli OUAS ve basit horlama hastalarına öneren görüşler de mevcuttur. 33,34 Genel sağlık durumu iyi olmayan bireylerde, KBB ve/veya anatomik problemlerin mevcudiyetinde, periodontal hastalık ve yetersiz ağız hijyeni söz konusu olduğunda, santral uyku apnesi varlığında ve TME problemi mevcudiyetinde oral aparey tedavisi uygulanmamalıdır. $7,31,34$ Piyasada $80^{\prime}$ den fazla oral aparey bulunmaktadır. ${ }^{35}$

OUAS tedavisi için kullanılan apereyler Mandibulayı Önde Konumlandıran Apareyler ${ }^{1,36}$ (Mandibular Advancement Devices=MAD $=$ MA tipi oral apareyler), Dili Önde Tutan Apareyler ${ }^{37}$ (Tongue Retaining Devices=TRD) ve Damağı Stabilize Eden Apareyler ${ }^{20}$ (Palate Lifting Appliances=PLA) olarak 3 gruba ayrımaktadır.

\section{a) Mandibulayı Önde Konumlandıran Apareyler (MA, MAD, MİKA)}

Mandibulayı önde konumlandıran apareylerle mandibula maksimum protrüzyonun yaklaşık \% 50-75'i kadar ileri alınıp dişler arası vertikal mesafe bir miktar arttırılarak dil ve yumuşak damak daha anteriorda konumlandırılır. Böylece orofarengeal hava yolunda bir artış elde edilir. Apareyin sagittal aktivasyon miktarı kesin olduğu halde, literatür incelendiğinde vertikal mesafe konusunda ortak bir görüş olmadığı gözlenmektedir.

Mandibular repositioner apareyleri hava yolunu çeşitli şekilde açarak fonksiyon görürler. Bu apareyler: ${ }^{11,12,22,23,36}$

1- Direk dili ileriye çekerek'

2- Genioglossus kas aktivitelerini arttırarak,

3- Mandibulayı ve hyoid kemiği stabilize ederek

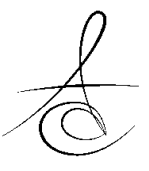


çenenin açılmasını ve dilin geriye düşmesini engelleyerek işlev görürler. ${ }^{36}$

Resim 2'de Selçuk Üniversitesi Diş Hekimliği Protetik Diş Tedavisi kliniğinde hastaya uygulanmış bir MAD apareyi görülmektedir.

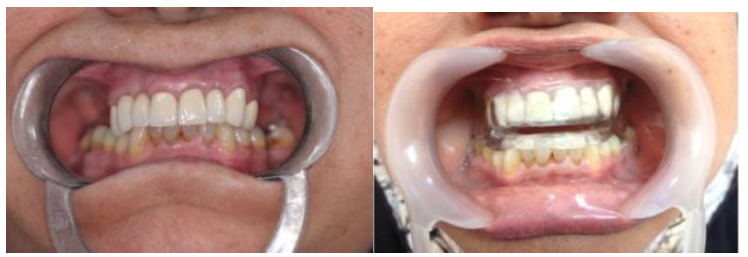

Resim 2. Mandibulayı Önde Konumlandıran Apareylerin Hastaya Uygulanışı

b) Dili Önde Konumlandıran Apareyler (Tongue Retaining Device = TRD)

Dili önde konumlandıran apareyler (TRD) uyku sırasında burun solunumu geçişlerinin önlenemeyen boyutlarını azaltmak için dizayn edilmiştir. TRD tipi apareyler uyku esnasında dili anterior dişlerin önüne çekerek dilin posteriora düşmesini ve hava yolunun tıkanmasını engellerler. TRD uyku sırasında negatif hava basıncıyla önde yer alan bir balonla dili önde tutar. Nasal havayolunda tıkanıklık olan hastalar için hava yolu tüpü içeren modifiye TRD de mevcuttur. FDA, horlama ve apne tedavisi için TRD'yi onaylamış$\operatorname{tır}^{37}$ (Resim 3).

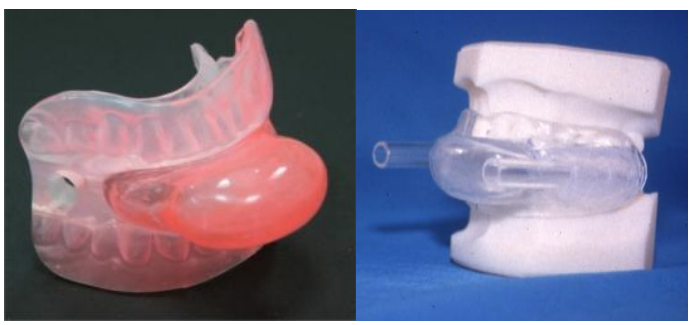

Resim 3.Dili Önde Konumlandıran Aparey (TRD) ve Modifiye TRD ${ }^{20}$

\section{(Palate Lifting Appliances =PLA)}

c) Damağı Stabilize Eden Apareyler

Damağı stabilize eden apareyler ise yumuşak damağı yukarı kaldırıp uvula pozisyonunu değiştirirler. Konforlu apareyler olmadıkları için hastalar tarafından daha az tolere edilirler ve nadiren kullanılırlar. Yumuşak damağı stabilize ederek horlamaya neden olan vibrasyonu azaltırlar (Resim 4). ${ }^{20}$

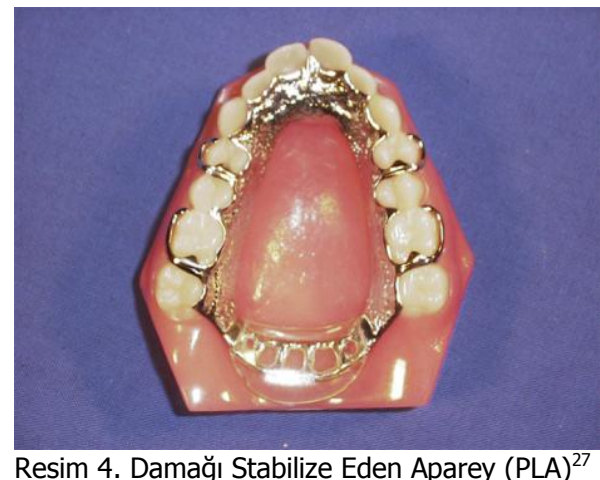

\section{OUAS Hastalarının Diş Hekimliği Yönünden Değerlendirilmesi \\ Oral aparey tedavisi görecek olan hastalar için} American Sleep Disorders Dental Society (ASDA) bir tedavi protokolü hazırlamıştır ${ }^{31,38-41}$. Bu protokole göre:

1) Hastanın dental ve medikal anamnezi alınır.

2) Tıp doktoru tarafından yollanan rapor incelenir.

3) Dental muayene yapılır. Dental muayene şu basamakları içermektedir: yumuşak doku muayenesi, periodontal durumun incelenmesi, okluzyonun kontrolü, TME muayenesi, diş ve restorasyonların kontrolü, intraoral ve parafonksiyonel alışkanlıkların incelenmesi, hastadan sefalometrik, panaromik gerekirse periapikal film istenmesi ve teşhis ve aparey yapımı için gerekli modellerin elde edilmesi.

4) Hasta için en uygun aparey tipine karar vererek yapılan apareyin hasta ağzına uyumlanması

5) Aparey etkinliğinin anlaşılabilmesi için hastadan polisomnografi alınması

6) Tedavi etkin görülürse ilk 1 sene 3 ayda bir, sonraki senelerde ise 6 ayda bir hastanın kontrole gelmesi uygun görülmüştür ${ }^{31,38}$.

Oral apareylerin ucuz olması , klinikte harcanan zamanın daha az olması, kolay taşınabilirliği, hastalar tarafından daha rahat tolere edilebilir olması, noninvaziv ve reversible bir yöntem olması, apareyin kullanımının hastanın günlük yaşantısını etkilememesi, dişli veya dişsiz hastalarda uygun aparey seçenekleri olması gibi pek çok avantajı mevcuttur ${ }^{42}$.

Bunun yanı sıra oral aparey kullanımı ağız kuruluğu, TME disfonksiyon, diş hareketleri ve okluzyon bozuklukları gibi yan etkilere neden olabilir. Hayat boyu kullanım gerektirmesi ve hastanın tedaviye uyumunun kontrol edilememesi gibi bir takım dezavantajları da mevcuttur. ${ }^{2}$

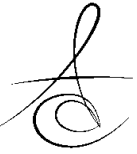




\section{SONUÇ}

OUAS tedavisinde NCPAP uygulamasının altın standart olduğu kabul edilmektedir. Ancak oral aparey tedavisi de daha ucuz ve hastalar tarafından daha kolay tolere edilebilir bir tedavi yöntemi olması nedeniyle günümüzde OUAS tedavisinde sıklıkla tercih edilmektedir.

\section{KAYNAKLAR}

1. Vuorjoki-Ranta TR, Lobbezoo $F$, Tuomilehto $H$, Könönen M, Pihakari A, Ahlberg J. Health 2013;5:1-5.

2. Battagel JM, L'Estrange PR. The cephalometric morphology of patients with obstructive sleep apnea. Eur J Orthod 1996;18:557-69.

3. Kyung HS, Park YC, Pae EK. Obstructive sleep apnea patients with the oral appliance experience pharyngeal size and shape changes in three dimensions. Angle Orthod 2004;75:15-22.

4. Kuhl W.History of clinical research on the sleep apnea syndrome. Respiration 1997;64:5-10.

5. Kryger MH. Fat, sleep and Charles Dickens: Literary and medicalcontributions to the understanding of sleep apnea. Clin Chestmed 1985;6:555-62.

6. Guilleminault C, Eldridge FL, Dement WC. Insomnia with sleep apnea: a new syndrome. Science 1973;181:856-8.

7. Ivanhoe JR, Cibirka RM, Lefebvre CA, Parr G. Dental considerations in upper airway sleep disorders: A review of the literature. J Prosthet Dent 1999;82:685-98.

8. Lawton HM, Battagel JM, Kotecha BA. Comparison of the Twin Block and Herbst Mandibular advancement splints in the treatment of patients with obstructive sleep apnea: a prospective study. Eur J Orthod 2005;27:82-90.

9. Johnston CD, Gleadhil IC,Cinnamond MJ,Gabbey J,Burdan D. Mandibular advancement appliances and obstructive sleep apnea: a randomized clinical trial. Eur J Orthod 2002;24:251-62.

10. Battagel JM, Johal A,Smith AM,Kotecha B. Postural variation in oropharyngeal dimensions in subjects with sleep disordered breathing: A cephalometric study. Eur J Orthod 2002;24:263-76.

11. Mossaz CF, Richter M,Oehlrich S. Case Report: Surgical orthodontic management of posttraumatic obstuctive sleep apne syndrome. Angle Orthod 1997;67:155-60.

12. Rose E, Staats R, Virchow C, Jonas IE. A comparative study of two mandibular advancement appliances for the treatment of obstructive sleep apnoea. Eur J Orthod 2002;24:191-8.

13. Robertson C. Cranial base considerations between apnoeics and non-apnoeic snorers, and associated effects of long term mandibular advancement on condylar and natural head position. Eur J Orthod 2002;24:353-61.

14. Şahin A. Obstrüktif uyku apne sendromunun fizyopatolojisi, Obstrüktif Sleep Apne Sendromu, Türkiye Akciğer Hastalıkları Vakfı Yayınları. 1993;1:19-29

15. Ivanhoe, JR, Cibirka RM, Lefebvre CA, Parr G. Dental Considerations in Upper Airway Sleep Disorders: A Review of the Literature. J Prosthet Dent 1999;82:685-98

16. Johal A, Battagel JM. Current Principles in the Management of Obstructive Sleep Apnoea with Mandibular Advancement Appliances. British Dental Journal 2001;190:532-6.

17. Clark GT, Arand D, Chung E, Tong D. Effect of Anterior Mandibular Positioning on Obstructive Sleep Apnea. Am Rev Respir Dis 1993;147:624-9.

18. Lyons, MF, Cameron DA, Banham SW. Snoring, Sleep Apnoea and the Role of Dental Appliances. Dent Update 2001;28:254-6.

19. Yoshida, K. Effect of a Prosthetic Appliance for Treatment of Sleep Apnea Syndrome on Masticatory and Tongue Muscle Activity. J Prosthet Dent 1998;79:537-44.

20. Türel $\mathrm{H}$. Basit horlama ve hafif dereceli obstrüktif uyku apne sendromu olgularında MA tipi oral apareyin tedavi etkinliğinin incelenmesi. Gazi Üniversitesi Doktora Tezi 2007.

21. Grisius R, Moore DJ. Miscellaneous prostheses, Obstructive sleep apnea. In: Beumer J, Curtis TM, Marunick MT. Maxillofacial rehabilitation: Prosthodontic and surgical considerations. 2nd ed. St. Louis; ABD: 1996.p: 515.

22. Meyer JB, Knudson RC. The sleep apnea syndrome. Part II: treatment. J Prosthet Dent 1990;63:320-4.

23. Naismith SL, Winter VR, Hickie IB, Cistulli PA. Effect of oral appliance therapy on neurobehavioral functioning in obstructive sleep apnea: a 
randomized, controlled trial. J Clin Sleep Med 2005; 1:374-80.

24. Cote EF. Obstructive sleep apnea: An orthodontic concern. Angle Orthod 1988;28:293-307.

25. Thornton WK. Combined CPAP. Oral appliance therapy. Sleep and Breathing 2002;3:16-21.

26. Denbar MA. A case study involving the combination of treatment of an oral appliance and auto-titrating CPAP unit. Sleep and Breathing 2002;6:125-7.

27. Ferguson KA, Ono $T$, Lowe $A A$, Keenan SP, Fleetham JA. A randomized crossover study of an oral appliance vs nasal-continuous positive airway pressure in the treatment of mild-moderate obstructive sleep apnea. Chest 1996;109:1269-75.

28. Chesson AL Jr, Ferber RA, Fry JM, GriggDamberger $M$, Hartse KM, Hurwitz TD, Johnson S, Kader GA, Littner M, Rosen G, Sangal RB, Schmidt Nowara W, Sher A. Practice parameters for the indications for polysomnography and related procedures. Sleep. 1997;20:406-22.

29. Kokturk O, Ulukavak Ciftci T. Obstruktif uyku apne sendromu CPAP/BPAP tedavisi. Tuberkuloz ve Toraks Dergisi. 2002;50:317-34.

30. Eskofi M, Cline C, Nilner M, Israelsson B. Treatment of sleep apnea in congestive heart failure with a dental device. The effect on brain natriuretic peptide and quality of life. Sleep Breath 2006;10:90-7.

31. Schmidt-Nowara W, Lowe A, Wigand L, Cartwright R, Perez-Guerra F, Mean S. Practice parameters for the treatment of snoring and obstructive sleep apnea with oral appliances. SleepAnd Breathing 1995;18:511-3.

32. Kurtulmus $\mathrm{H}$, Cotert HS, Basoglu OK, Bilgen C. Cephalographic and polysomnographic evaluation of excellent efficiacy of the mandibular advancement splint in a patient with moderate obstructive sleep apnea syndrome. Atatürk Üniv Dis Hek Fak Derg 2009;9:31-6.

33. Rose E, Germann M, Sorichter S, Jones IE. Case control study in the treatment of obstructive sleepdisordered breathing with a mandibular protrusive appliance. J Orofac Orthop 2004;65:489-500.

34. Rose E, Staats R. Der therapeutische efekt eines aktivators bei der therapie der obstruktiven schlafapnoe-eine longitidinal studie Deutsche Zahnarztliche Zeitschrift 2002;57:473-80.
35. Lowe AA. Orthodontists and oral sleep-disordered breathing. Am J Orthod Dentofac Orthop 2006;129:194-5.

36. Sarı E, Liebermann L, Karaçay Ş. Oral Horlama ve Obstrüktif Uyku Apnesinde Kullanılan Apareyler. Türk Ortodonti Dergisi 2006;19:181-96.

37. Samelson $\mathrm{C}$. The role of tongue retaining device treatment of snoring and obstructive sleep apnea. CDS Rev 1988:9;44-7

38. Lowe AA, Schmidt-Nowara WW. Oral appliance therapy for snoring and apnea. Sleep 1995; 18;501-10

39. Lowe A. Treating obstructive sleep apnea: The case for oral appliances. American Journal of Orthodontics and Dentofacial Orthopedics. 2012;142:434-40.

40. Kushida CA, Morgenthaler TI, Littner MR, Alessi CA, Bailey D, Coleman J Jr, Friedman $L$, Hirshkowitz M, Kapen S, Kramer M, Lee-Chiong T, Owens J, Pancer JP. American Academy of Sleep Medicine: Practice parameters for the treatment of snoring and obstructive sleep apnea with oral appliances: an update for 2005. Sleep. 2006; 29:240-3.

41. Steven D. Bender. Oral appliance therapy for sleep-related breathing disorders. Operative Techniques in Otolaryngology 2012; 23, 72-8.

42. Lamant J, Baldwin DR, Mateljan R, Pantin C, Finucane KE. Mandibular advancement splints of obstructive sleep apnea. Europ J Orthod 1998;20:293-7.

\section{Yazışma Adresi}

Arş. Gör. Dt. Eda ÖZDERE

Selçuk Üniversitesi,

Diş Hekimliği Fakültesi,

Protetik Diş Tedavisi A.B.D., KONYA

Tel.: 03322231681

e-mail: edaozdere@yahoo.com 